\title{
The Roles of IncRNA in Myocardial Infarction: Molecular Mechanisms, Diagnosis Biomarkers, and Therapeutic Perspectives
}

OPEN ACCESS

Edited by:

Lei Deng,

Central South University, China

Reviewed by:

Yi Huan,

Fujian Women and Children Hospital,

China

Jingpu Zhang,

Henan University of Urban

Construction, China

*Correspondence:

Lianhong Li

lilianhong917@126.com

Specialty section:

This article was submitted to

Molecular and Cellular Pathology,

a section of the journal

Frontiers in Cell and Developmental

Biology

Received: 15 March 2021

Accepted: 20 August 2021

Published: 16 September 2021

Citation:

Xie L, Zhang Q, Mao J, Zhang J and $L i L$ (2021) The Roles of IncRNA

in Myocardial Infarction: Molecular Mechanisms, Diagnosis Biomarkers,

and Therapeutic Perspectives.

Front. Cell Dev. Biol. 9:680713.

doi: 10.3389/fcell.2021.680713

\author{
Luhan Xie ${ }^{1}$, Qingqing Zhang ${ }^{1}$, Jun Mao', Jun Zhang ${ }^{2}$ and Lianhong $\mathrm{Li}^{1 *}$ \\ ${ }^{1}$ Department of Pathology and Forensic Medicine, College of Basic Medical Sciences, Dalian Medical University, Dalian, \\ China, ${ }^{2}$ Department of Teaching Affairs, Dalian Medical University, Dalian, China
}

In recent years, long non-coding RNAs (IncRNAs) have been demonstrated to be associated with many physiological and pathological processes in cardiac. Recent studies have shown that IncRNAs are expressed dynamically in cardiovascular diseases and participate in regulation through a variety of molecular mechanisms, which have become a critical part of the epigenetic and transcriptional regulatory pathways in heart development, as well as the initiation and progress of myocardial infarction. In this review, we summarized some current research about the roles of IncRNAs in heart development and myocardial infarction, with the emphasis on molecular mechanisms of pathological responses, and highlighted their functions in the secondary changes of myocardial infarction. We also discussed the possibility of IncRNAs as novel diagnostic biomarkers and potential therapeutic targets for myocardial infarction.

Keywords: myocardial infarction, long non-coding RNAs, ceRNA, exosome, biomarker

\section{INTRODUCTION}

According to the latest report of the World Health Organization (WHO), cardiovascular diseases are still the leading cause of death worldwide, and coronary heart disease (CHD) accounts for the largest proportion. Myocardial infarction (MI) is a serious manifestation of CHD, which results from acute and prolonged deficits in the supply of oxygen, nutrients, and survival factors to the myocardium, trigger a series of severe biochemical and metabolic perturbations in the cardiomyocyte. This imbalance is most caused by sudden and prolonged ischemia. In contrast to other cardiac diseases, where multiple processes contribute to pathogenesis, cell death in the ischemic area is the initial and central event of myocardial infarction. Besides, infarction is associated with a variety of structural and functional consequences, and the most irreversible of which is the death of cardiomyocytes (CMs) (Del Re et al., 2019). However, cardiomyocytes are terminally differentiated cells and have lost their mitotic ability (Mercola et al., 2011), so the regeneration capacity of the heart in adult mammals is limited. Meanwhile, infarct size is important as a major determinant of subsequent cardiac dysfunction and mortality (Del Re et al., 2019).

For a long time, proteins have been regarded as the center of the gene regulatory networks. Nevertheless, with the development of new techniques, only $2 \%$ of protein-coding genes were found in the mammalian genome (Shabalina and Spiridonov, 2004), whereas the vast majority of the human genome is transcribed into non-coding RNAs, including long non-coding RNAs (lncRNAs). Genome-wide association studies have shown that a significant portion of the genetic variation related to human disease resides in the non-coding regions of the genome 
(Partridge et al., 2020; Van Nostrand et al., 2020). To date, ncRNAs with gene regulatory functions have been identified and shown to play a role in various biological processes, including epigenetic and transcriptional regulation (Rinn and Chang, 2012), embryogenesis and development (Pauli et al., 2011), pluripotency and differentiation (Guttman et al., 2011; Kretz et al., 2013), protein biosynthesizing process, as well as participate in dynamic developmental and cell-specific expression patterns.

The expression of lncRNA in different tissues is more specific than protein-coding genes, indicating the function of lncRNAs is closely related to the functional specificity of tissues (Ransohoff et al., 2018). Besides, most lncRNAs showed tissuespecific expression patterns similar to master transcription factors. A recent study characterized cardiac-enriched lncRNAs. By comparing RNA sequencing data from mouse hearts, livers, and skin cells, the study identified 321 cardiac-expressed lncRNAs. Among them, 117 transcripts were abundant and highly cardiac enriched. $67 \%$ of the cardiac-enriched lncRNAs were also highly expressed in isolated cardiomyocytes, indicating that the majority of the highly expressed lncRNAs in the mouse hearts are expressed by cardiomyocytes (Matkovich et al., 2014). Therefore, IncRNAs may represent important regulatory factors of development and disease processes in hearts, as well as novel disease biomarkers or therapeutic targets for cardiovascular disease and its risk factors. A deeper understanding of the functional and molecular mechanisms of lncRNAs will have profound implications for cardiovascular disease and may provide new opportunities for intervention in disease progression.

In this review, we summarized some of the studies on the critical roles of lncRNAs in many different aspects of cardiac physiology and pathology, especially in myocardial infarction, as well as discussed the possibility of lncRNAs as novel diagnostic biomarkers and therapeutic targets for myocardial infarction. We also discussed the existing challenges and future trends in the clinical practice and lab research of lncRNAs in MI.

\section{IncRNAs AND ROLES IN CARDIAC DEVELOPMENT AND DIFFERENTIATION}

lncRNAs are defined as non-coding RNA sequences greater than $200 \mathrm{nt}$ in length, some lncRNAs can produce small peptides, but the vast majority of lncRNAs do not encode proteins. According to the NON-CODE database ${ }^{1}$, the number of lncRNAs is 549,813 in total, including 173,112 and 131,974 lncRNA genes for human and mice, respectively, and many lncRNAs appear to be cardiacspecific, or cardiac-enriched (Grote et al., 2013; Klattenhoff et al., 2013; Matkovich et al., 2014; Ounzain et al., 2015).

lncRNA is an important part of the gene regulatory network for embryonic stem cell differentiation, alteration of its expression can interfere with the maintenance and differentiation (Guttman et al., 2011). Changes in transcriptional networks during heart development and homeostasis may lead to congenital heart disease and chronic heart

${ }^{1}$ http://www.noncode.org problems (Srivastava, 2006; Bruneau, 2008). A genomewide transcriptional profiling study confirmed that lncRNAs showed significant stage-specific expression manner in cardiac differentiation and abundant genes related to development, morphogenesis, and transcription. Moreover, the expression of lncRNAs is correlated with adjacent genes, suggesting that IncRNAs play a cis-regulatory role in cardiomyocyte differentiation and cardiac development (Wamstad et al., 2012).

The Mesp1 gene (post mesoderm gene 1) is one of the earliest genes expressed in heart cells which is essential for heart development (Lescroart et al., 2014). AK143260, named Braveheart $(B v h t)$, a mouse-specific lncRNA that is highly expressed in mouse embryonic stem cells (ESCs) and cardiomyocytes. During ESCs differentiation, Bvht acts as upstream of Mesp1, regulating the transformation of neonatal mesoderm to cardiac development (Klattenhoff et al., 2013). Moreover, during cardiomyocyte differentiation, Bvht mediates cardiac epigenetic regulation in cardiovascular core gene networks by activating PRC2 component SUZ12 and transcription factors. Lateral mesoderm-specific lncRNA Fendrr is also essential for normal heart and body wall development during tissue differentiation in mice embryos. Fendrr deficiency shows myocardial dysfunction, affects the development of the heart and body walls and contributes to embryonic death. Besides, Fendrr deletion affects the modification of epigenetic promoters and the expression of transcriptional regulators (Grote et al., 2013). It has also been suggested that Fendrr may need to balance $\mathrm{H} 3 \mathrm{~K} 4$ and $\mathrm{H} 3 \mathrm{~K} 27$ methylation during mesodermal differentiation to coordinate genetic programming (Rizki and Boyer, 2015).

The transition from the pluripotent stage to the differentiated stage is accompanied by a large number of epigenetic changes (Beermann et al., 2016). Most of the lncRNAs detected in human left ventricle samples contain DNaseI hypersensitivity loci and epigenetic markers of active signal transcription, indicating that cardiac lncRNA expression is correlated with epigenetic modification (Yang et al., 2014). Many novel lncRNAs with potential roles in cardio-genesis are also differentially regulated in human heart diseases (Ounzain et al., 2015). Therefore, lncRNAs are critical components in cardiac development, and participate in cardiac transcription, and serve as epigenetic regulators in cardiac gene expression.

\section{IncRNAs AND THEIR MOLECULAR MECHANISM DURING MI}

Previous studies have shown that, compared with the control group, multiple transcriptome changes occurred in the process of MI, with the largest transcriptome changes occurring in the acute phase (day 1) (Zhang X. et al., 2021), and the largest expression of lncRNA also occurred in the day 1 of MI. Meanwhile, these dysregulated lncRNAs are associated with the initiation and progression pathway of MI (Shi et al., 2020). Inflammation and cardiomyocyte apoptosis are the main characteristics of myocardial infarction (Marchant et al., 2012). After the initial ischemic event, the acute sudden death of cardiomyocytes in 
the infarcted zone rapidly activates the innate immune pathway, thereby trigger a strong inflammatory response (Frangogiannis, 2014). In the murine study, mice were sacrificed on the first-day post-MI, and differentially expressed lncRNA in infarcted heart tissue has a strong relationship with the inflammation-related pathways (Liu et al., 2014; Zangrando et al., 2014). These results suggest that lncRNA may participate in the regulation of MI in the acute phase through the inflammatory response.

Studies on the effect of lncRNAs have shown that lncRNAs regulate gene expression at both transcriptional and posttranscriptional levels. The complementary sites on lncRNA enable them to recognize and bind to mRNAs, miRNAs, or other lncRNAs and conduct highly specific regulation. Protein binding sites allow them to interact with proteins to produce various ribonucleoprotein particles with different biological functions (Thum and Condorelli, 2015). The function of lncRNA is related to its structure and genome localization. Based on their genomic organization and structure, lncRNAs can be categorized as being sense, antisense, intergenic, intronic, and bidirectional (Ponting et al., 2009; Figure 1) in contrast to miRNAs, lncRNAs have a diversity of molecular functioning classed as being signal, decoy, guide, or scaffold (Devaux et al., 2015; Figure 2 and Table 1).

\section{Decoy}

An increasing number of ceRNAs have emerged that regulate numerous processes of myocardial infarction through miRNA inhibition. miRNAs inhibit the translation or promote the degradation of mRNAs by binding to the complementary sequence of their $3^{\prime}$ untranslated region ( $3^{\prime}$-UTR), thus regulating gene expression, while lncRNAs can regulate the expression of mRNAs by acting as miRNAs sponges to interact with miRNAs (Cesana et al., 2011). The lncRNA-miRNA-mRNA axis can associate lncRNAs with the various regulatory functions in myocardial infarction.

lncRNA AK017121, named cardiac apoptosis-related lncRNA (CARL), acting as ceRNA in MI. PHB2 inhibits mitochondrial fission and apoptosis, miR-539 targeting PHB2 and subsequently up-regulating the level of PHB2 to inhibited mitochondrial fission and apoptosis. Meanwhile, the overexpression of CARL inhibiting the expression of miR-539. Modulation of the CARLmiR-539-PHB2 axis may provide a novel approach for the treatment of apoptosis and myocardial infarction (Wang et al., 2014). The lncRNA AK079427, named autophagy promoting factor (APF), can binds with miR-188-3p as a ceRNA and lead to increased ATG7 levels, which enhances cardiac autophagy in cardiomyocytes after MI. Indicating that APF may be viewed as a biomarker target in MI, and APF-miR-188-3p-ATG7 is a regulated axis of myocardial cell autophagy (Wang K. et al., 2015).

In addition to cell apoptosis and autophagy, ceRNA has also been shown to regulate necrosis in myocardial infarction. A long non-coding RNA, named necrosis-related factor (NRF), was closely related to necrotic death of cardiomyocytes by acting as an endogenous RNA sponge that interacted with miR-873. Experiments show that RIPK1 and RIPK3 participate in $\mathrm{H}_{2} \mathrm{O}_{2}$-induced cardiomyocytes necrosis, miR-873 suppresses the translation of RIPK1/RIPK3 and inhibits RIPK1/RIPK3mediated necrotic cell death in cardiomyocytes, which reduces myocardial infarct size upon ischemia/reperfusion (I/R) injury in the animal model. Indicating NRF is transcriptionally activated by p53 upon I/R injury, binds miR-873, leading to increased cardiomyocyte necrosis mediated by RIPK1/RIPK3 (Wang et al., 2016). Another study showed that RIPK1/RIPK3-mediated cardiomyocyte necrosis can also be regulated by lncRNA H19. Fas-associated protein with death domain (FADD) influencing the formation of RIPK1/RIPK3 complexes in $\mathrm{H}_{2} \mathrm{O}_{2}$-treated H9C2 cells and MI mice, while $\mathrm{H} 19$ attenuates necrotic responses by targeting miR-103/107 and FADD (Wang J.X. et al., 2015). $\mathrm{H} 19$ was not only involved in myocardial cell necrosis, but also participated in the regulation of myocardial cell apoptosis. As a competitive endogenous RNA of miR-877-3p (Li et al., 2019) and miR-675 (Luo et al., 2019), H19 can regulate apoptosis of cardiomyocytes by regulating mitochondrial apoptosis pathway and targeting PPAR $\alpha$, respectively.

Moreover, lncRNAs can also bind transcription factors, thereby inhibiting their binding to genes. A lncRNA called cardiac autophagy inhibitory factor (CAIF) inhibiting the autophagy of cardiac cells during myocardial infarction by directly interacting with the transcription factor p53, then blocking its binding to the myocardin promoter region (Liu et al., 2018). Recent findings have shown that lncRNAs can also compete with miRNAs and interact with target mRNAs to inhibit gene expression. In some cases, the stability and function of lncRNAs can be reduced by regulating specific miRNAs. Besides, some lncRNAs can produce miRNAs themselves that inhibit target mRNAs (Yoon et al., 2014).

\section{Guide}

In addition to mediating nucleic acid interactions, lncRNAs can also act as guide RNAs, forming complexes with proteins or DNAs through molecular interactions, acting on adjacent or distal genes in a cis- or trans- way, and guiding the complexes to locate specific target genes to regulate various biological phenomena. Cell characteristics in organisms are determined by epigenetic factors that regulate specific gene expression programs. These epigenetic factors, such as chromatin modification complexes and DNA methyltransferases, activate and inhibit specific genes by enzyme modifying chromatin and DNA (Moran et al., 2012).

For example, lncRNAs can modify transcription by recruiting chromatin modifiers and transcription factors to genomic sites to regulate gene expression ( $\mathrm{Ng}$ et al., 2012; Grote et al., 2013). In the placenta, lncRNA Kcnq1ot1 interacts with specific transcriptional repressors by recruiting chromatin remodeling complexes to establish a lineage-specific transcriptional silencing pattern (Pandey et al., 2008). In cardiac, Kcnq1ot1 recruits DNA methyltransferase 1 (DNMT1) to the RUNX3 promoter region and inhibit Runx3 expression, regulating the proliferation and apoptosis of CMEC and induces inflammatory response during myocardial infarction (Wang et al., 2019). MCM3 (minichromosomal maintenance 3) is the initiator of DNA replication and cell cycle process, which can inhibit cardiomyocyte proliferation. IncRNA CPR represses MCM3 expression by directly interacting and recruiting DNMT3A to the $\mathrm{CpG}$ island of the MCM3 promoter, thereby preventing 


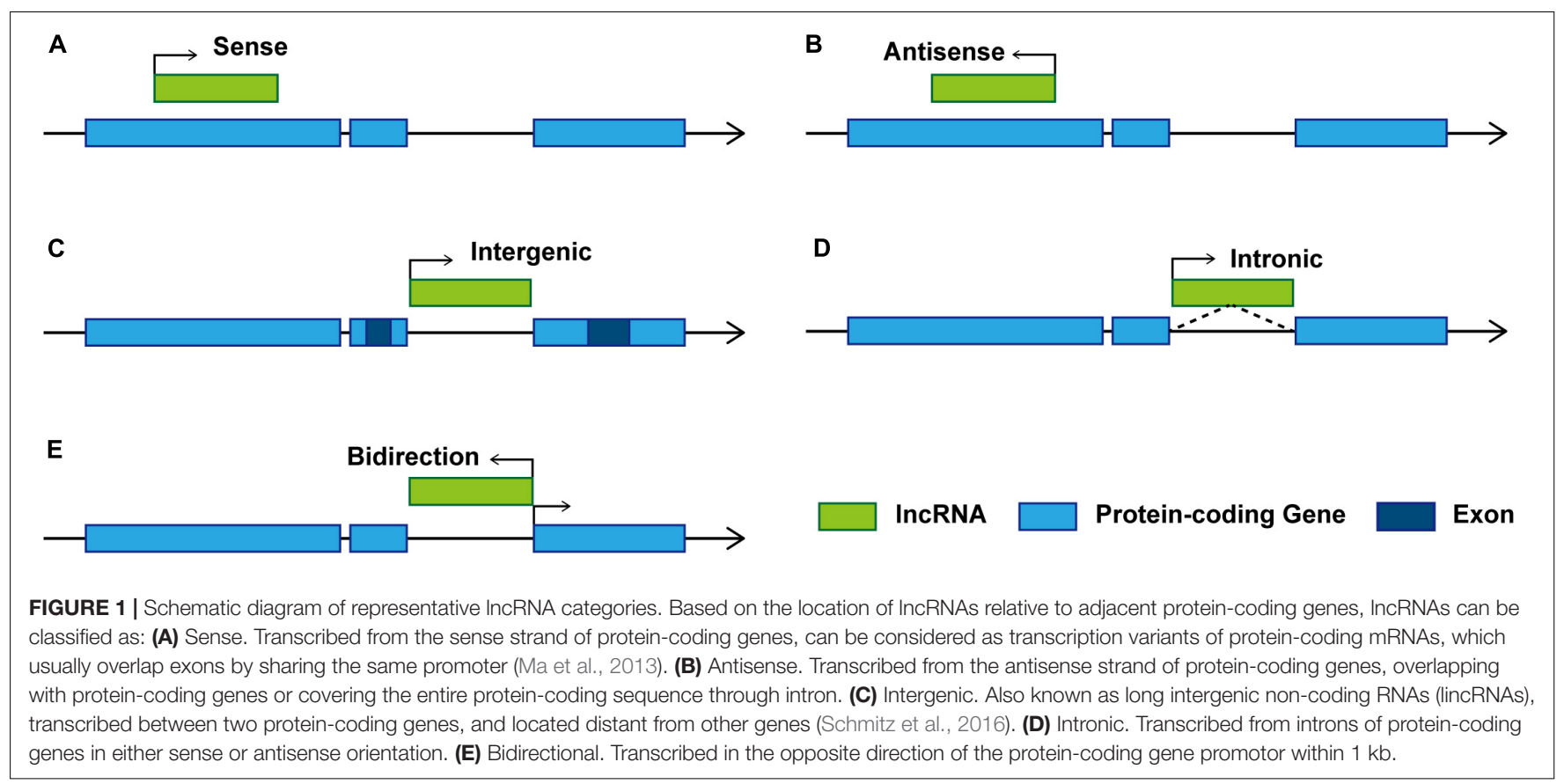

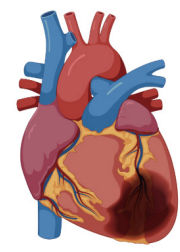

Myocardial Infarction
A

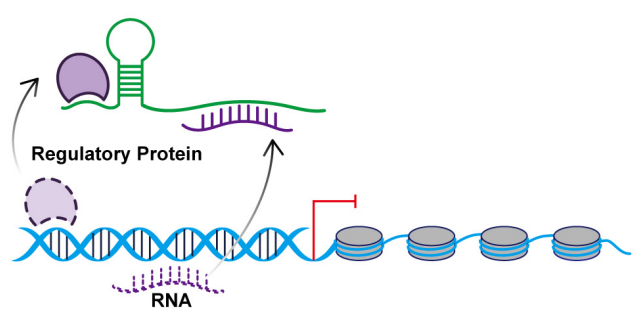

C

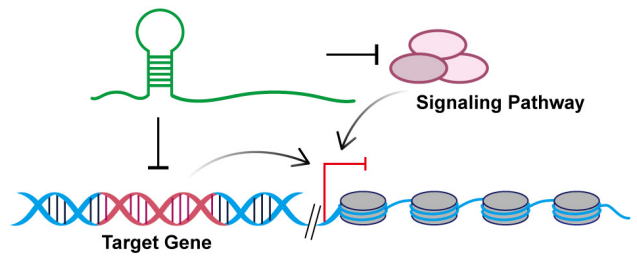

B

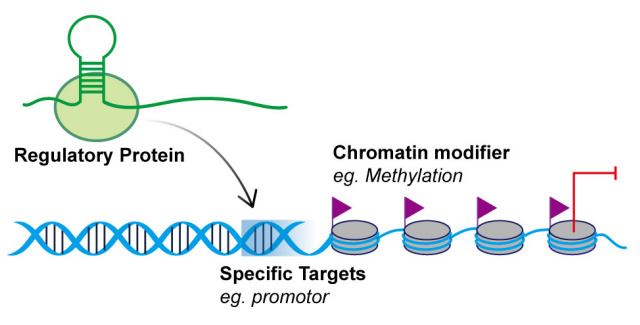

D

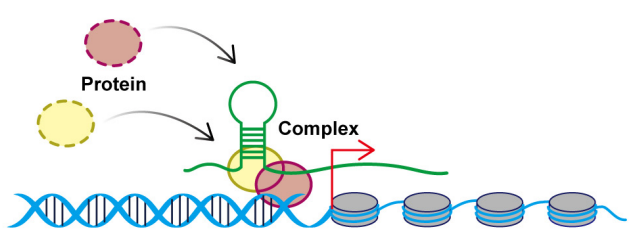

FIGURE 2 | Models of four known IncRNA molecular mechanisms of action in myocardial infarction. (A) Decoy. IncRNAs can act as sponges to interact with regulatory proteins or RNAs away from their targets. (B) Guide. IncRNAs can recruit and combine regulatory proteins or DNAs through molecular interactions and guiding the complexes to the specific targets. (C) Signal. IncRNAs respond to specific stimuli and participant in the regulation of gene expression by regulating signaling pathways through cis- or trans- way. (D) Scaffold. IncRNAs may serve as scaffolds to bring proteins together in biological regulation.

cardiomyocyte proliferation. Meanwhile, lncRNA CPR deficiency can accelerate cardiomyocyte proliferation, promote myocardial repair and improve cardiac function after myocardial infarction (Ponnusamy et al., 2019).

Besides, lncRNAs can binding to target DNA as a DNA-RNA heteroduplex, DNA-DNA-RNA triple strand (Hung and Chang, 2010). IncRNA Sarrah is significantly down-regulated in aging and infarct hearts, regulates NRF2 gene transcription by recruiting gene promoters CRIP2 and p300 to form a DNA-DNA-RNA triple helical structure. Silencing Sarrah can induce apoptosis of cardiomyocytes, conversely, an increase of Sarrah in vivo can improve cardiomyocyte survival rate and myocardial systolic function after AMI (Trembinski et al., 2020).

\section{Signal}

Under different stimulus conditions, lncRNA will be specifically transcribed and participate in the conduction of special signaling pathways as signal transduction molecules. Signal lncRNAs mediate gene expression through cis- or trans- action. In cis, 
TABLE 1 | LnCRNAs with characterized functions and target genes in myocardial infarction.

\begin{tabular}{|c|c|c|c|}
\hline LncRNA & Target & Function & References \\
\hline CARL & miR-539/PHB2 & Inhibit mitochondrial fission and myocardial apoptosis in Ml. & Wang et al., 2014 \\
\hline APF & miR-188-3p/ATG7 & Regulates autophagic program and autophagic cell death after MI. & Wang K. et al., 2015 \\
\hline NRF & miR-873/RIPK1-RIPK3 & Regulate cardiomyocyte necrosis and myocardial injury in I/R. & Wang et al., 2016 \\
\hline \multirow[t]{3}{*}{$\mathrm{H} 19$} & miR-103/107/FADD & Regulate programmed Necrosis and Myocardial I/R Injury & Wang J.X. et al., 2015 \\
\hline & miR-877-3p/Bcl-2 & Inhibit the mitochondrial apoptotic pathway in myocardial & Li et al., 2019 \\
\hline & miR-675/PPAR $\alpha$ & Regulate cell death and IR injury & Luo et al., 2019 \\
\hline CAIF & p53-mediated myocardin & Repress autophagic cell death and alleviate MI. & Liu et al., 2018 \\
\hline Kcnq1ot1 & RUNX3 & $\begin{array}{l}\text { Recruits DNMT1 to the RUNX3 promoter region and regulates CMEC } \\
\text { viability and inflammatory response during MI. }\end{array}$ & Wang et al., 2019 \\
\hline CPR & MCM3 & $\begin{array}{l}\text { Interact and recruit DNMT3A to the CpG island of MCM3 promoter, then } \\
\text { inhibit cardiomyocyte proliferation and cardiac function after MI }\end{array}$ & Ponnusamy et al., 2019 \\
\hline Sarrah & NRF2 & $\begin{array}{l}\text { Recruit CRIP2 and p300 to form complex and regulate cardiomyocytes } \\
\text { apoptosis in AMI. }\end{array}$ & Trembinski et al., 2020 \\
\hline FAF & FGF9/FGFR2/PI3K/Akt & Regulate myocardial cell apoptosis in AMI. & Shi et al., 2019 \\
\hline SLC8A1-AS1 & SLC8A1/cGMP-PKG & Reduce infarct size and ischemia damage in AMI. & Guo et al., 2019 \\
\hline Airn & $\operatorname{lgf2bp2}$ & $\begin{array}{l}\text { Affects the translation of Igf2bp2, silencing Airn can increase apoptosis and } \\
\text { affect the physiological function of cardiomyocytes. }\end{array}$ & Hosen et al., 2018 \\
\hline ZFAS1 & SERCA2a & Inhibitor of SERCA2a and limits systolic function during MI. & Zhang et al., 2018 \\
\hline Ahit & SUZ12 & $\begin{array}{l}\text { Downregulating the expression of MEF2A and preventing cardiac } \\
\text { hypertrophy through epigenomic modulation. }\end{array}$ & Yu J. et al., 2020 \\
\hline ANRIL & WDR5-HDAC3 & Form protein complexes and increase ROS level. & Zhang et al., 2020 \\
\hline
\end{tabular}

lncRNAs can regulate the expression of adjacent genes, enhancer lncRNAs synthesized at enhancers can activate adjacent genes cis through DNA loops. In trans, it can affect the expression of genes across chromosomes (Batista and Chang, 2013). Although some lncRNAs are cis-regulators (Koerner et al., 2009), recently, loss of function tests has verified that most lncRNAs have trans-regulatory effects, such as knockout of some lincRNAs with no effect on adjacent genes or low effect on other genes (Ørom et al., 2010; Guttman et al., 2011).

After being transcribed, some lncRNA molecules have the function of regulating downstream gene transcription. The expression of lncRNA FAF is downregulated in ischemia-hypoxic cardiomyocytes and heart tissues of AMI rats. IncRNA FAF regulates the expression of FGF9/FGFR2 in myocardial cells in the form of positive feedback, then inhibits apoptosis by affecting PI3K/Akt signaling pathway (Shi et al., 2019). Microarray analysis showed that lncRNA SLC8A1-AS1 was down-regulated in AMI, prevented myocardial injury by down-regulating SLC8A1 and activating the cGMP-PKG signaling pathway, inhibiting the release of pro-inflammatory factors and reducing the infarct size to alleviate myocardial ischemia damage (Guo et al., 2019). IncRNA antisense Igf2r RNA (Airn, also known as "Air") is an imprinted gene transcribed and expressed from the parent chromosome. Its transcription is necessary to inhibit several imprinted genes on the parent chromosome in a tissue-specific and allele-specific manner. Its transcription plays a key role in overlapping gene silencing (Wang and Chang, 2011). In addition to its function as an imprinting gene, Airn can post-transcriptionally control protein-coding genes in cardiomyocytes. In $\mathrm{HL}-1$ cells treated with $\mathrm{H}_{2} \mathrm{O}_{2}$, Airn binds to insulin-like growth factor 2 mRNA-binding protein 2 (Igf2bp2) and affects the translation of Igf2bp2, thereby controlling the downstream mRNA. Silencing Airn can increase apoptosis and affect the physiological function of cardiomyocytes (Hosen et al., 2018). It indicates that Airn belongs to translation-modulating lncRNA, which can modify protein function by directly interacting with the protein itself or binding partners.

ZnFX1 antisense RNA 1 (ZFAS1) belongs to lncRNA and has been reported to promote the occurrence and development of a variety of cancers. However, a series of studies on ZFAS1 in acute myocardial infarction (AMI) has shown that ZFAS1 is significantly differentially expressed between AMI patients and healthy people. The circulation level of ZFAS1 can be used as an independent predictor of AMI and is considered a novel biomarker. Besides, the combination of ZFAS1 with lncRNA CDR1As could increase the power of sensitivity and specificity of the prediction of AMI (Zhang et al., 2016). The expression of ZFAS1 was also significantly increased in the cytoplasm and sarcoplasmic reticulum of the MI mice model and hypoxic cell model. At the subcellular level, ZFAS1 causes $\mathrm{Ca}^{2+}$ overload in cardiomyocytes and induces mitochondrial swelling and a decrease in mitochondrial membrane potential. At the molecular level, multiple sequence fragments of ZFAS1 were found to be complementary to the $3^{\prime}$-UTR of SERCA2a (sarcoplasmic reticulum $\mathrm{Ca}^{2+}$-ATPase $2 \mathrm{a}$ ), limiting its activity and expression, and activating apoptotic pathways. These results suggest that ZFAS1 may interact with SERCA2a mRNA through direct antisense complementation to induce the degradation of SERCA2a mRNA and change the expression level (Zhang et al., 2018; Jiao et al., 2019). Thus, ZFAS1 may be an endogenous SERCA2a inhibitor that inhibits its function by restricting its intracellular protein-bind SERCA2a levels. 


\section{Scaffold}

Some lncRNAs compose scaffolds through specific secondary structures and bind to different protein molecules to form complexes. These complexes are involved in cis or trans epigenetic regulation of genes as transcriptional activators or inhibitors (Nagano and Fraser, 2011; Guttman and Rinn, 2012). The association between lncRNA and disease may be related to scaffold capacity (Ribeiro et al., 2018). For example, lncRNA can affect mRNA splicing, translation, or degradation by binding to mRNA or protein components of the RNP complex (Gong and Maquat, 2011; Rinn and Chang, 2012; Batista and Chang, 2013).

Expression of lncRNA Ahit was upregulated in the hearts of mice with aortic contraction. Both in vivo and in vitro experiments confirmed that Ahit binds and recruited SUZ12, the core protein of $\mathrm{PRC} 2$, to the promoter of MEF2A, acting as a scaffold and initiates $\mathrm{H} 3 \mathrm{~K} 27 \mathrm{me} 3$ to mediate the downregulation of MEF2A, thereby regulating cardiac hypertrophy. Meanwhile, clinical data confirmed that Ahit was significantly elevated in serum samples from patients with hypertensive heart disease. These results indicate that Ahit is a kind of lncRNA that plays an important scaffold role through epigenomic regulation, modulates chromatin remodeling in the dense state ( $\mathrm{Yu}$ J. et al., 2020). Coronary atherosclerotic heart disease (CAD) often causes myocardial ischemia and myocardial infarction, leading to sudden cardiac death. The research showed that the expression of ANRIL in CAD patients was significantly higher than that in healthy people. As the scaffold, ANRIL could promote the binding of WDR5 and HDAC3 to form protein complexes that regulate the expression of target genes through histone modification, up-regulate ROS level and promote the phenotypic transformation of the human aortic smooth muscle cell, which lead to the progression of CAD (Zhang et al., 2020).

\section{EXOSOME}

In multicellular organisms, cells exchange information with neighboring or distant cells by secreting individual molecules or extracellular vesicles (EVs) of intracellular origin, including exosomes, microvesicles (Tkach and Théry, 2016; Barile et al., 2017). Exosomes are the smallest subset of EVs with a diameter ranging from 30 to $150 \mathrm{~nm}$. Unlike other EVs, exosomes have special membranous surface molecules that allow them to target the recipient cell and release their contents into the cell, thereby altering the state of the recipient cell (Tkach and Théry, 2016). Exosomes carry a variety of molecules, including low molecular compounds, lipids, proteins, and various nucleic acids, such as DNA, mRNA, and ncRNA (Valadi et al., 2007). The composition of exosomes varied greatly in different cell types and microenvironments, even exosomes released by the same type of cells under healthy and pathogenic conditions are also different. Therefore, exosomes can be used as both diagnostic markers and therapeutic targets for diseases.

Exosomes are released by a variety of heart cells, including cardiomyocytes, endothelial cells, cardiac fibroblasts, and cardiac progenitor cells (Barile et al., 2017). Hypoxia is an effective exosomal-releasing stimulator in cardiomyocytes, inducing the heart to release EVs containing antiapoptotic proteins (e.g., pro-apoptotic and anti-apoptotic factors) (Chistiakov et al., 2016). During AMI, the damaged cardiomyocytes produce exosomes with angiogenesis, anti-apoptosis, mitosis, and increased growth factor content to induce repair and healing of the infarct myocardium. RNA-seq analysis showed that lncRNA AK139128 was overexpressed from both hypoxic cardiomyocytes and its exosomes. Interestingly, hypoxic exosomes increased the expression of AK139128 in recipient cardiac fibroblasts (CFs) after co-culture with CFs. Besides, exosome AK139128 from hypoxic CMs can stimulate CFs apoptosis and inhibit proliferation (Wang and Zhang, 2020).

Some studies have confirmed lncRNA-UCA1 might participate in the process of ischemia and hypoxia of cardiomyocytes (Wang Q.S. et al., 2020). Exosome lncRNAUCA1 deriving from hypoxia mesenchymal stem cells (hMSCs) plays a cardioprotective role through the miR-873-5p/XIAP axis. Different from healthy people, the plasma of AMI patients contains exosomes rich in lncRNA-UCA1, and circulating exosomes lncRNA-UCA1 may be a promising new biomarker for the diagnosis of AMI (Sun et al., 2020). Another lncRNA contained in hMSCs exosomes is KLF3-AS1. In vivo transfection of KLF3-AS1 exosomes in rats, and in vitro incubation of hypoxic cardiomyocytes, also KLF3-AS1 exosomes, both confirmed that overexpression of KLF3-AS1 resulted in the reduction of myocardial infarction area and apoptosis, and KLF3-AS1 acted as an RNA sponge-miR-138-5p to mediate the expression of SIRT1, thereby regulating cardiomyocyte apoptosis and progression of myocardial infarction (Mao et al., 2019).

Previous studies have demonstrated that atorvastatin (ATV) pretreatment can enhance the efficacy of mesenchymal stem cells (MSCs) in the therapeutic of AMI (Yang et al., 2008), also, the combination therapy of ATV and MSCs can significantly improve cardiac function after AMI (Yang et al., 2009). Exosomes isolated from ATV-pretreated mesenchymal stem cells (MSC ${ }^{\mathrm{ATV}}$-Exo) increased cell survival and angiogenesis, improved cardiac function, and reduced infarct size and myocardial cell apoptosis, both in vitro and in vivo. Molecular mechanism studies have shown that lncRNA H19 is a mediating role of $\mathrm{MSC}^{\mathrm{ATV}}$-Exo in regulating miR-675 expression and the activation of pro-angiogenic factor VEGF and intercellular adhesion molecule-1 (ICAM-1). Meanwhile, the downregulation of lncRNA H19 decreased the cardioprotective effect of MSC $^{\text {ATV }}$-Exo. These results suggested that lncRNA H19 mediated the cardioprotective effect of MSC-derived exosome in promoting angiogenesis and cardioprotective effects in myocardial infarction (Huang P. et al., 2020).

A large number of studies have shown that ncRNAs contained in exosomes secreted by stem cells or somatic cells can serve as biomarkers for myocardial infarction, as well as myocardial protection and myocardial regeneration after infarction injury (Khan et al., 2015; Gallet et al., 2017). Circulating exosomal lncRNAs ENST00000556899.1 and ENST00000575985.1 were significantly up-regulated in AMI patients compared with healthy people, they showed related with clinical parameters, including inflammatory biomarkers, prognostic indicators, 
and myocardial damages markers, functioning as potential biomarkers for predicting the prognosis of patients with AMI (Zheng et al., 2020).

Exosomes have lipid bilayer, compared with the lncRNAs in extracellular fluid, the lncRNAs in packaged exosomes are highly stable because of the protection from enzymatic degradation, which may have long-term stable existence in the cardiovascular system (Cheng et al., 2019). Therefore, exosomes lncRNA could be a novel biomarker and therapeutic approach (Table 2 ).

\section{LncRNAs AND SECONDARY CHANGES OF MI}

\section{Ischemia and Reperfusion}

Reducing myocardial infarct size and preserving the left ventricular systolic function is necessary for STEMI (STsegment elevated myocardial infarction) patients. The most effective therapeutic strategies used in clinical practice include primary percutaneous coronary intervention (PPCI) and drug intervention (Hausenloy, 2012). However, the process of restoring coronary blood flow to the coronary artery to ischemic tissue may induce cardiomyocyte death and myocardial injury, a phenomenon termed "myocardial reperfusion injury" (Yellon and Hausenloy, 2007). Previous studies on rodent ischemia-reperfusion (I/R) models have shown that I/R leads to dysregulation of IncRNA expression in heart tissues, and these dysregulated IncRNAs are associated with downstream molecular mechanisms of ischemia-reperfusion (Lin et al., 2018; Lou et al., 2021).

lncCIRBIL, lncRNA Cardiac Injury-Related Bclaf1-Inhibiting LncRNA, reduced in ischemia-reperfusion heart tissue, and lncCIRBIL knockout mice aggravated cardiac I/R damage. Studies have shown that lncCIRBIL is located in the cytoplasm of cardiomyocytes and can directly bind to Bclaf1 (Bcl2-associated transcription factor 1) to inhibit its nuclear translocation to activate the p53 transcriptional activity, which is a necessary step leading to cardiac I/R injury. Therefore, lncCIRBIL and Bclafl are key regulators of cardiac $I / R$ injury and potential therapeutic targets for ischemic heart disease. This is a study on the interaction between lncRNA and protein as the mechanism of myocardial ischemia-reperfusion (Zhang Y. et al., 2021). During myocardial ischemia-reperfusion, there are also ceRNA mechanisms. Endogenous lncRNA HOTAIR

TABLE 2 | Exosomes IncRNAs of myocardial infarction.

\begin{tabular}{lcll}
\hline LncRNA & Target & Function & References \\
\hline UCA1 & miR-873-5p/XIAP & $\begin{array}{l}\text { Improve the level of } \\
\text { antiapoptotic protein and } \\
\text { cardiac protection }\end{array}$ & $\begin{array}{l}\text { Sun et al., } \\
2020\end{array}$ \\
KLF3-AS1 & miR-138-5p/SIRT1 & $\begin{array}{l}\text { Inhibit cell pyroptosis and } \\
\text { attenuate Ml progression. }\end{array}$ & Mao et al., \\
& miR- & $\begin{array}{l}\text { Mediate the cardioprotective } \\
\text { effect of MSC-derived }\end{array}$ & Huang P. \\
H19 & et al., 2020 \\
& exosomes and promoted & \\
& & &
\end{tabular}

is an important negative regulator of oxidative stress and cardiomyocyte apoptosis in myocardial I/R injury. HOTAIR can prevent oxidative stress, cardiomyocyte apoptosis, and cardiac dysfunction by regulating the Zeste homology 2/microRNA451/calcium-binding protein 39 (EZH2/miR-451/CAB39) axis enhancer to activate AMPK $\alpha$ (Meng et al., 2020).

\section{Myocardial Fibrosis}

After myocardial infarction, myocardial fibrosis is a characteristic and inevitable event. Cardiac fibroblasts secrete excessive extracellular matrix (ECM), which eventually leads to collagenous scar replacing the dead ischemia myocardium (Frangogiannis, 2012). The generation and maintenance of scars is the key to prevent the heart from infarct area expanding. But excessive deposition of the ECM leads to heart stiffness, which can eventually lead to heart failure and death (Travers et al., 2016; Frangogiannis, 2017). lncRNA H19 was significantly upregulated in the infarct area and reaches an exceptionally high level at post-MI day 4, then competes with COL1A1 to form the H19-YB-1 complex under hypoxia, resulting in decreased COL1A1 expression, thus preventing ECM deposition and cardiac remodeling (Choong et al., 2019).

Another study reveals a novel function and molecular mechanism of IncRNA in myocardial fibrosis induced by myocardial infarction. IncRNA 554 was highly expressed in cardiac fibroblasts after myocardial infarction for 28 days. In vitro, knockout of lncRNA 554 significantly reduced in CFs migration and ECM expression. In vivo, knockout of lncRNA 554 inhibited myocardial fibrosis and improved myocardial function. TGF- $\beta 1$ inhibitor (TEW-7197) could significantly inhibit the fibrosis-promoting function of lncRNA 554 in CFs. These results indicated that the effect of lncRNA 554 on MI-induced myocardial fibrosis was dependent on the TGF- $\beta 1$ signaling pathway (Luo et al., 2020). Wisper (WISP2 super enhancement factor associated RNA) is a myocardial fibroblast enriched lncRNA that regulates myocardial fibrosis. The expression level was correlated with the degree of myocardial fibrosis in mouse models of myocardial infarction and aortic stenosis patients. Functionally, Wisper modulates cardiac fibroblast gene expression programs that are critical for cellular characterization, extracellular matrix deposition, proliferation, and survival (Micheletti et al., 2017).

\section{Heart Failure}

Heart failure (HF) is a common disease after AMI (Velagaleti et al., 2008; Ezekowitz et al., 2009), and the incidence of HF increases significantly after MI and is associated with mortality (Lewis et al., 2003). Studies have shown that lncRNAs are differentially expressed in various HF models in mice and humans. After pressure overload, which is induced by aortic contraction, the left ventricular whole gene of heart failure mice was changed, among which 135 lncRNAs were expressed in the left ventricle of heart failure mice (Lee et al., 2011).

The expression level of lncRNA in the human HF tissues was also changed. A study of 40 human LV samples through nextgeneration sequencing revealed significant differences in mRNA, miRNA, and lncRNA expression patterns between ischemic and 
non-ischemic failure hearts, most of these lncRNAs are encoded by mitochondrial DNA. In this study, the authors found that expression patterns of lncRNAs, not mRNAs or miRNAs, are more sensitive in the discrimination of ischemic and nonischemic heart failure (Yang et al., 2014). The above results indicate that IncRNA can be a good biomarker in heart disease states. Besides, this study also found a strong positive correlation between lncRNA expression and its adjacent genes, suggesting that there may be a cis-regulated transcription mechanism in heart failure myocardium.

\section{Cardiac Remodeling}

Loss of myocardial function is a pathological feature of AMI, the injured heart undergoes structural and functional changes to maintain cardiac outcome, such changes in the heart are term as cardiac remodeling. Since cardiac remodeling affects ventricular function and is associated with the patient's prognosis (Bostan et al., 2020), the phenomenon of ventricular remodeling in MI patients has attracted more and more attention. Studies have shown that ventricular remodeling in the infarct area and adjacent areas lead to the loss of shortening and contraction with dyssynchronization, resulting in decreased cardiac output, as well as the increase in ventricular volumes (van den Borne et al., 2010).

lncRNA Chast (cardiac hypertrophy-associated transcript) was up-regulated in hypertrophic heart tissue and transverse aortic constriction-operated mice. Chast suppresses Pleckstrin homology domain-containing protein family $M$ member 1 (Plekhm1) then prevents cardiac remodeling and cardiomyocyte autophagy (Viereck et al., 2016). Among the 20 upregulated lncRNAs in MI mice, the myocardial infarct-associated transcript 1 (MIRT1) and MIRT2 were significantly upregulated. In the time-process analysis, the expressions of MIRT1 and MIRT2 progressive increased after MI and peaked $24 \mathrm{~h}$, then returned to baseline 2 days later. On the other hand, MIRT1 and MIRT2 levels correlated with the expression of multiple left ventricular remodeling genes. Expression of MIRT1 and MIRT2 displayed progressive increases after induction of MI, suggesting that MIRT1 and MIRT2 may contribute to left ventricular remodeling after myocardial infarction (Zangrando et al., 2014).

Details of lncRNAs modes of functions in MI-induced secondary changes are shown in Table 3.

\section{IncRNAs AND ROLES AS NOVEL BIOMARKERS OF MI}

The European Society of Cardiology (ESC) and the American College of Cardiology (ACC) have introduced sensitive cardiac biomarkers to the definition of MI by biochemical and clinical methods (Alpert et al., 2000). Cardiac troponin I (cTnI) and T (cTnT) are preferred biomarkers for the assessment of myocardial injury and can be defined as a specific subtype of MI (Thygesen et al., 2018). High sensitivity-cTn assays have been widely used in nowadays routine assays. The definition of myocardial infarction, published in 2018 by the Journal of the American Heart Association, states that myocardial infarction is the presence of acute myocardial injury with the rise and/or fall of cTn with at least one value above the 99th percentile upper reference limit (URL) in the context of the evidence of acute myocardial ischemia (Thygesen et al., 2018). cTns have guided treatment decisions for CVD for decades. However, the increased sensitivity of hs-cTn (high-sensitivity cardiac troponin) also increases the likelihood of false positives in a healthy population (Schulte et al., 2020), so there is a need to improve and supplement existing biomarkers, with circulating $\operatorname{lncRNA}$ potentially contributing to the specificity of protein biomarkers.

A study tested five lncRNAs (aHIF, ANRIL, KCNQ1OT1, MIAT, MALAT1) that associated with cardiac pathology in the blood samples from MI patients, results shows that the levels of certain lncRNAs in peripheral blood cells are regulated after $\mathrm{MI}$ and associated with $\mathrm{LV}$ dysfunction (Vausort et al., 2014). Levels of aHIF, KCNQ1OT1, and MALAT1 were higher in MI patients than in healthy volunteers $(P<0.01)$, and levels of ANRIL were lower in patients with MI $(P=0.003)$. Interestingly, Levels of ANRIL were associated with cardiovascular risk factors, such as age, diabetes mellitus, and hypertension. In multivariable and reclassification analyses, ANRIL and KCNQ1OT1 improved the prediction of left ventricular dysfunction by a model, including demographic features, clinical parameters, and cardiac biomarkers.

A genome-wide association study of MI patients in Iceland has found an association between MI and common sequence variations on chromosome 9p21. Carriers were 1.64 times more likely to suffering MI than non-carriers, and 2.02 times more likely to develop MI in early-stage cases (Helgadottir et al., 2007). The strongest genetic susceptibility locus for coronary artery disease is located in the chromosome 9p21 gene desert (Schonrock et al., 2012). The INK4 locus is located on human chromosome 9p21 and encodes proteins called p16INK4a, ARF, and P15INK4B (Gil and Peters, 2006). It was found that antisense non-coding RNA (ANRIL), a long-stranded noncoding RNA, transcribed from the INK4 site could bind and recruit PRC1 and PRC2 to the INK4 locus, thus inhibiting the transcription of p16INK4A and p15INK4B (Kotake et al., 2011). p16INK4a, ARF, and P15INK4B play a key role in regulating cell proliferation, cell aging, and apoptosis (Kim and Sharpless, 2006). These changes are important features of atherosclerosis and are the root cause of myocardial infarction and CAD (Minamino and Komuro, 2007). Therefore, it is worth noting that this variant, in addition to affecting MI, may also increase the risk of CAD.

According to research, in the plasma of patients at the early and late stage of myocardial infarction, seven lncRNAs were differentially expressed during left ventricular remodeling. And the expression of LIPCAR, a mitochondrial source long intergenomic non-coding RNA, is associated with cardiac remodeling, and the elevation of LIPCAR levels in patients with HF may be significantly associated with a higher risk of mortality, which can be used to independently predict cardiovascular mortality in patients with chronic heart failure (Kumarswamy et al., 2014). Another research data confirmed that circulating long non-coding RNA cardiac hypertrophy-associated transcript 
TABLE 3 | LncRNAs in secondary changes of myocardial infarction.

\begin{tabular}{|c|c|c|c|}
\hline LncRNA & Target & Function & References \\
\hline IncCIRBIL & Bclaf1 & Reduced infarcted area after I/R and cardiac protection. & Zhang Y. et al., 2021 \\
\hline HOTAIR & $\mathrm{EZH} 2 / \mathrm{miR}-451 / \mathrm{CAB} 39$ & Regulates oxidative stress and cardiac myocardial apoptosis during l/R & Meng et al., 2020 \\
\hline $\mathrm{H} 19$ & COL1A1 & $\begin{array}{l}\text { Form H19-YB-1 complex to decrease COL1A1 expression and } \\
\text { preventing ECM deposition and cardiac remodeling after Ml. }\end{array}$ & Choong et al., 2019 \\
\hline SAIL & SAFB & Regulating cardiac fibrosis by promoting SAFB bind to rpb1. & Luo et al., 2021 \\
\hline Safe & Sfrp2 mRNA & Binding Sfrp2 mRNA $3^{\prime}-U T R$ and inhibited TGF- $\beta$ - induced fibrosis. & Hao et al., 2019 \\
\hline Cfast & $\begin{array}{l}\text { COTL1/TRAP1/TGF- } \beta \\
\text { signaling pathway }\end{array}$ & $\begin{array}{l}\text { Competitively inhibits the interaction between COTL1 and TRAP1, } \\
\text { thereby enhancing fibrosis-related gene expression and myofibroblasts } \\
\text { transdifferentiating into CFs. }\end{array}$ & Zhang F. et al., 2021 \\
\hline IncRNA 554 & TGF- $\beta 1$ signaling pathway & Regulate CFs migration and ECM expression following MI. & Luo et al., 2020 \\
\hline Chast & Plekhm1 & Prevent cardiac remodeling and hypertrophy. & Viereck et al., 2016 \\
\hline Wisper & TIAR & $\begin{array}{l}\text { Reduce the development of myocardial fibrosis after Ml and prevent } \\
\text { adverse remodeling. }\end{array}$ & Micheletti et al., 2017 \\
\hline
\end{tabular}

(CHAST) was an independent predictor of myocardial systolic function in patients with early AMI $(P<0.05)$, and CHAST could be used as a candidate biomarker for cardiac remodeling. Compared with the control group, CHAST level was higher in patients with AMI, and the expression level of CHAST was positively correlated with cardiac systolic function at $24 \mathrm{~h}$ $(P<0.05)$ (Wang X. et al., 2020).

The characteristics of an ideal biomarker include four aspects: high sensitivity, high specificity, easy detection, and minimal invasiveness (Bostan et al., 2020). High sensitivity refers to increased concentration after the onset of disease, rapid release, and long half-life to allow diagnosis. High specificity means that it is specifically expressed in cardiac tissue and is not present in healthy people's hearts. Also, the ideal biomarker needs to be easy to detect, effective in clinical diagnosis and treatment and can help predict prognosis (Bostan et al., 2020). The ideal biomarker should satisfy multiple characteristics making it difficult to identify a single parameter that satisfies all of these; therefore, the combination of biomarker analysis in clinical diagnosis can improve the accuracy, while lncRNA as a biomarker still needs more accurate detection and verification.

\section{IncRNAs AND THERAPEUTIC PERSPECTIVE}

A large number of studies have shown that abnormal expression of lncRNA can lead to cardiovascular diseases, and heartspecific gene regulation shows great potential in preventing and alleviating heart diseases, indicating that lncRNA is a new target with diagnostic efficacy and therapeutic potential. Unlike protein, lncRNAs are easy to synthesis and delivery, restoring abnormal lncRNA expression in the disease through gene therapy may be a new therapeutic strategy. RNA-based therapy is divided into RNA molecules used as therapeutic drugs (Crooke et al., 2018) and RNA-targeted small-molecule drugs (Warner et al., 2018). Cytoplasmic lncRNAs can be downregulated by siRNA or shRNA. For nuclear lncRNAs, excessive expression of lncRNA can be inhibited by antisense oligonucleotide to inhibit inappropriate upregulation (Rincon et al., 2015).

\section{Adeno-Associated Virus Vectors}

Adeno-associated virus vectors (AAV) are single-stranded DNA vectors capable of persistent transgenic expression in target tissues, including the heart (Levy et al., 2020). The use of lncRNA-CAREL transgenic mice, as well as adenovirus-mediated endogenous CAREL silencing in vivo, all could significantly promote cardiac regeneration and improved cardiac function after myocardial infarction (Cai et al., 2018). Adenovirusmediated silencing of endogenous $\operatorname{lncDACH} 1$ promotes cardiac regeneration in MI mice and activates the proliferative potential of cardiomyocytes, which provides a novel therapeutic strategy for ischemic heart disease (Cai et al., 2020). AAV9 is the most effective serotype of cardiac gene transfer, and some mouse model studies have reported the superiority in cardiac gene transfer (Pacak et al., 2006). The recombinant AAV9 vector carrying the lncRNA Oip5-as1 promoter (AAV9-Oip5-as1) was injected into the myocardial tissue of MI rats for gene transfer therapy. The results showed that AAV9-Oip5-as1 injection effectively increased Oip5-as1 expression in the heart of MI rats, which significantly inhibited the increase in myocardial infarction size (Niu et al., 2020). These results suggest that lncRNA can regulate the proliferation of cardiomyocytes and postnatal heart development. Targeting lncRNA may protect the heart after myocardial infarction by inducing the replication of myocardial cells, which may be considered as a new therapeutic method to promote the repair of the damaged heart (Thum, 2018). These results indicate that targeting lncRNA may protect the heart after myocardial infarction, and AAV targeting therapy of hearttargeted gene delivery is effective, which may be considered as a new therapeutic approach to promote damaged heart repair.

\section{Antisense Oligonucleotides}

One of the advantages of oligonucleotide drugs is to upregulate specific target genes or proteins, which is difficult to do with small molecule drugs before. Antisense oligonucleotides (ASO) delivered into cells through complementary base pairs, target intracellular mRNAs or functional ncRNAs, and treat diseases by leading to gene silencing or controlling gene expression through different mechanisms, including inhibition of the activity of 
natural antisense transcripts, interaction with ncRNA promoter binding sites, and blocking of regulatory and/or miRNA binding sites in the 3-'UTR (Yu A.M. et al., 2020). The antisense oligonucleotide method has been successfully applied in clinical practice, but the application of anti-lncRNA in the cardiovascular field is still in the pre-clinical stage. Since lncRNA have multiple target genes and target proteins, these antisense sequences must be chemically modified to improve the structural stability and tissue distribution of nucleotides (Landmesser et al., 2020).

With the invention of genome-editing techniques such as CRISPR/Cas9, it is possible to generate and identify RNA mutants. However, the artificial phenotype caused by the CRISPR off-target effect still needs to be overcome. While most of the current research is still carried out at the cellular level or in small rodent model systems, research in large mammal studies or human ex vivo studies needs to be advanced quickly to facilitate the future clinical success of the next generation of ncRNA-based therapies (Huang C.K. et al., 2020). Besides, there is growing evidence that extracellular vesicles may be a very promising area of research for targeted cardiac delivery (Sahoo et al., 2021).

\section{IncRNAs Regulating Cell Cycle Progression}

Exogenous delivery of lncRNAs can inhibit cell death and restore cardiac function after myocardial infarction. In addition, some studies have shown that lncRNAs also could regulate cardiomyocyte proliferation by enhancing or inhibiting cell cycle processes. Comprehensive analysis of transcriptome changes from human fetal-to-adult heart transition found that differentially expressed lncRNAs may be potential targets involved in cardiac regeneration after $\mathrm{MI}$.

For example, the IncRNA CPR mentioned above is significantly higher in the adult heart than in the fetal stage. CPR inhibits MCM3 expression by directly interacting and recruiting DNMT3A to $\mathrm{CpG}$ islands of MCM3 promoter region, thereby prevent cardiomyocyte proliferation. The results show that CPR is a negative regulator of cardiomyocyte proliferation in postnatal and adult hearts (Ponnusamy et al., 2019). On the contrary, lncRNA ECRAR (Endogenous Cardiac Regeneration-associated Regulator) may serve as an effective gene target for heart (Chen et al., 2019). ECRAR promotes myocardial regeneration in postnatal and adult rat hearts and reduces adverse remodeling after myocardial infarction. ECRAR was transcriptionally upregulated by E2F1, and then directly bound to and promoted the phosphorylation of ERK1/2, resulting in downstream activation of cyclin D1 and cyclin E1 activation, which in turn activated E2F1. The E2F1-ECRAR-ERK1/2 formed a positive feedback loop to drive cell cycle progression and promoted CM proliferation after myocardial infarction.

\section{DISCUSSION}

\section{IncRNAs and Current Challenges}

The discovery of non-coding RNAs, such as lncRNAs, have given valuable insights into the molecular mechanisms of cardiovascular diseases such as myocardial infarction, also provides us with a new understanding of the pathogenesis of MI. But there are still many obstacles to overcome before lncRNAs can be used in clinical practice.

Firstly, considering the versatility of lncRNA in the pathophysiological process of the human body, off-target hits of interactions may lead to adverse effects, so a major problem with the use of lncRNAs in therapy is the highly cardiospecific targeted drug delivery systems. Although lncRNA is low conserved in sequence, it has high tissue specificity. According to unsupervised cluster analysis and RNA-seq analysis, the majority of lncRNAs have a tissue-specific expression (Cabili et al., 2011). Therefore, with the development of oligonucleotide delivery and gene therapy, we thought it is necessary to find highly specific and efficient targeting delivery systems to regulate the target lncRNA.

Secondly, although many studies have provided many potential therapeutic targets of lncRNAs and achieved success in animal models, these findings are not necessarily transferable to humans. Besides, most of the cardiac animal model are mice or rats, but rodent heart is significantly smaller than that of humans. It has been reported that the efficiency of gene transfer is usually inversely proportional to the size of the host (Ylä-Herttuala and Alitalo, 2003), so the animal heart cannot properly mimic the disease and treatment of the human heart. Therefore, the clinical transformation of lncRNAs still faces challenges. We believe that in future research, more effective methods are needed to study the specific functions and safety of lncRNAs in lab trials, and animal models that are more similar to human diseases are also needed for clinical transformation.

Thirdly, as an epigenetic regulatory factor, lncRNAs play a crucial role in gene regulation and disease pathogenesis, but their detailed molecular mechanisms have not been fully elucidated. The function of lncRNAs may be closely related to secondary structure due to a low level of sequence conservation and protein-coding ability. The biological functions of the lncRNAs require further investigation and deep study to provide a better understanding of the molecular structure in MI. In addition, the further development of lncRNA-targeted therapy depends on in-depth research on IncRNA, detailed structure and functional studies are more conducive to targeted and intervention design. Therefore, further research of the genomic and subcellular localization of lncRNAs, and their interaction relationships with proteins and other nucleic acids will provide additional insights into the understanding of mechanisms and functions, in which the expression level of lncRNAs are expected to be modulated in a tissue- and cell-specific manner.

Finally, the authenticity of lncRNA in myocardial infarction still needs more extensive verification before being considered as a true regulator of MI pathogenesis. Although many studies have found differentially expressed lncRNAs in MI, extensive verifications are still needed. Because an uncontrollable factor is a difference in type and number of cells in the infarct tissue, this may lead to false positives. Besides, different platforms and technologies may result in inconsistent results. Therefore, to obtain the most stable variational and reliable heart-specific lncRNAs in MI, it is necessary to record the whole transcriptome 
information of expression in specific cardiac regions at different developmental stages of myocardial ischemia or infarction.

\section{IncRNAs and Future Prospects}

lncRNAs participate in all aspects of physiology and pathology of the human body, and have been involved in cardiovascular disease, cancer, metabolism, and immunology. They play a role through molecular and biochemical mechanisms, from cis- to trans- regulation of gene expression, from epigenetic regulation of nucleus to post-transcriptional control of cytoplasm. Although we classify lncRNAs into four archetypes of molecular mechanisms above, some lncRNAs have the biological function of integrating multiple archetypes, and can control each level of multi-level regulation of gene expression pathway (Wapinski and Chang, 2011), which play a wide range of regulatory roles in almost every stage of gene expression. Besides, individual lncRNA can regulate several downstream genes, and one functional gene can be targeted by multiple lncRNAs.

The biology of IncRNA is a rapidly developing field in cardiovascular research, although some preliminary advances have been made, it is undeniable that the study of lncRNAs is still in its infancy. Further research is still needed to fully translate existing basic research findings into clinical treatment. Therefore, we believe that in future research on the mechanism and treatment of myocardial infarction, we need to further understand the lncRNA localization and structure, the interaction between proteins and nucleic acids, and the specific physiological function of lncRNAs in animal models. In addition, we also believe that it is necessary to consider the combination of multiple treatment methods of MI therapeutics strategies.

\section{REFERENCES}

Alpert, J. S., Thygesen, K., Antman, E., and Bassand, J. P. (2000). Myocardial infarction redefined-a consensus document of The Joint European Society of Cardiology/American College of Cardiology Committee for the redefinition of myocardial infarction. J. Am. Coll. Cardiol. 36, 959-969. doi: 10.1016/s07351097(00)00804-4

Barile, L., Moccetti, T., Marbán, E., and Vassalli, G. (2017). Roles of exosomes in cardioprotection. Eur. Heart J. 38, 1372-1379. doi: 10.1093/eurhe artj/ehw304

Batista, P. J., and Chang, H. Y. (2013). Long noncoding RNAs: cellular address codes in development and disease. Cell 152, 1298-1307. doi: 10.1016/j.cell.2013. 02.012

Beermann, J., Piccoli, M. T., Viereck, J., and Thum, T. (2016). Non-coding RNAs in development and disease: background, mechanisms, and therapeutic approaches. Physiol. Rev. 96, 1297-1325. doi: 10.1152/physrev.00041.2015

Bostan, M. M., Stătescu, C., Anghel, L., Șerban, I. L., Cojocaru, E., and Sascǎu, R. (2020). Post-myocardial infarction ventricular remodeling biomarkers-the key link between pathophysiology and clinic. Biomolecules 10:1587. doi: 10.3390/ biom 10111587

Bruneau, B. G. (2008). The developmental genetics of congenital heart disease. Nature 451, 943-948. doi: 10.1038/nature06801

Cabili, M. N., Trapnell, C., Goff, L., Koziol, M., Tazon-Vega, B., and Regev, A. (2011). Integrative annotation of human large intergenic noncoding RNAs reveals global properties and specific subclasses. Genes Dev. 25, 1915-1927. doi: 10.1101/gad.17446611

Cai, B., Ma, W., Ding, F., Zhang, L., Huang, Q., and Wang, X. (2018). The long noncoding RNA CAREL controls cardiac regeneration. J. Am. Coll. Cardiol. 72, 534-550. doi: 10.1016/j.jacc.2018.04.085

\section{CONCLUSION}

In summary, this review mainly reviews the regulatory gene networks of lncRNAs in cardiac development and pathology progress of myocardial infarction, and the secondary changes caused by myocardial infarction are also involved. Monitoring the quality and quantity of lncRNAs after myocardial infarction may become a new factor for the evaluation and prediction of prognosis, and lncRNAs may also become a new therapeutic target after myocardial infarction, providing a new idea for treatment. The abundance and diversity of differentially expressed lncRNA transcripts in diseases provide the possibility of diagnosis and treatment at the RNA level, but it also poses great challenges.

\section{AUTHOR CONTRIBUTIONS}

LX conceived the conception and wrote the manuscript. LL provided a lot of valuable advice and contributed to the revision. JM, QZ, and JZ provided many constructive suggestions and discussions. All authors read and approved the final manuscript.

\section{ACKNOWLEDGMENTS}

We would like to thank the members of the pathology and forensic department for their suggestions during this study.

Cai, B., Ma, W., Wang, X., Sukhareva, N., Hua, B., and Zhang, L. (2020). Targeting LncDACH1 promotes cardiac repair and regeneration after myocardium infarction. Cell Death Differ. 27, 2158-2175. doi: 10.1038/s41418-02 0-0492-5

Cesana, M., Cacchiarelli, D., Legnini, I., Santini, T., Sthandier, O., and Chinappi, M. (2011). A long noncoding RNA controls muscle differentiation by functioning as a competing endogenous RNA. Cell 147, 358-369. doi: 10.1016/j.cell.201 1.09 .028

Chen, Y., Li, X., Li, B., Wang, H., Li, M., and Huang, S. (2019). Long non-coding RNA ECRAR triggers post-natal myocardial regeneration by activating ERK1/2 signaling. Mol. Ther. 27, 29-45. doi: 10.1016/j.ymthe.2018.10.021

Cheng, M., Yang, J., Zhao, X., Zhang, E., Zeng, Q., and Yu, Y. (2019). Circulating myocardial microRNAs from infarcted hearts are carried in exosomes and mobilise bone marrow progenitor cells. Nat. Commun. 10:959. doi: 10.1038/ s41467-019-08895-7

Chistiakov, D. A., Orekhov, A. N., and Bobryshev, Y. V. (2016). Cardiac extracellular vesicles in normal and infarcted heart. Int. J. Mol. Sci. 17:63. doi: 10.3390/ijms17010063

Choong, O. K., Chen, C. Y., Zhang, J., Lin, J. H., Lin, P. J., and Ruan, S. C. (2019). Hypoxia-induced H19/YB-1 cascade modulates cardiac remodeling after infarction. Theranostics 9, 6550-6567. doi: 10.7150/thno.35218

Crooke, S. T., Witztum, J. L., Bennett, C. F., and Baker, B. F. (2018). RNA-targeted therapeutics. Cell. Metab. 27, 714-739. doi: 10.1016/j.cmet.2018.03.004

Del Re, D. P., Amgalan, D., Linkermann, A., Liu, Q., and Kitsis, R. N. (2019). Fundamental mechanisms of regulated cell death and implications for heart disease. Physiol. Rev. 99, 1765-1817. doi: 10.1152/physrev.00022.2018

Devaux, Y., Zangrando, J., Schroen, B., Creemers, E. E., Pedrazzini, T., and Chang, C. P. (2015). Long noncoding RNAs in cardiac development and ageing. Nat. Rev. Cardiol. 12, 415-425. doi: 10.1038/nrcardio.2015.55 
Ezekowitz, J. A., Kaul, P., Bakal, J. A., Armstrong, P. W., Welsh, R. C., and Mcalister, F. A. (2009). Declining in-hospital mortality and increasing heart failure incidence in elderly patients with first myocardial infarction. J. Am. Coll. Cardiol. 53, 13-20. doi: 10.1016/j.jacc.2008.08.067

Frangogiannis, N. G. (2012). Regulation of the inflammatory response in cardiac repair. Circ. Res. 110, 159-173. doi: 10.1161/circresaha.111.243162

Frangogiannis, N. G. (2014). The inflammatory response in myocardial injury, repair, and remodelling. Nat. Rev. Cardiol. 11, 255-265. doi: 10.1038/nrcardio. 2014.28

Frangogiannis, N. G. (2017). The extracellular matrix in myocardial injury, repair, and remodeling. J. Clin. Invest. 127, 1600-1612. doi: 10.1172/jci87491

Gallet, R., Dawkins, J., Valle, J., Simsolo, E., De Couto, G., and Middleton, R. (2017). Exosomes secreted by cardiosphere-derived cells reduce scarring, attenuate adverse remodelling, and improve function in acute and chronic porcine myocardial infarction. Eur. Heart J. 38, 201-211. doi: 10.1093/eurheartj/ ehw240

Gil, J., and Peters, G. (2006). Regulation of the INK4b-ARF-INK4a tumour suppressor locus: all for one or one for all. Nat. Rev. Mol. Cell. Biol. 7, 667-677. doi: $10.1038 / \mathrm{nrm} 1987$

Gong, C., and Maquat, L. E. (2011). IncRNAs transactivate STAU1-mediated mRNA decay by duplexing with 3' UTRs via Alu elements. Nature 470, 284-288. doi: 10.1038 /nature09701

Grote, P., Wittler, L., Hendrix, D., Koch, F., Währisch, S., and Beisaw, A. (2013). The tissue-specific lncRNA Fendrr is an essential regulator of heart and body wall development in the mouse. Dev. Cell 24, 206-214. doi: 10.1016/j.devcel. 2012.12.012

Guo, G. L., Sun, L. Q., Sun, M. H., and Xu, H. M. (2019). LncRNA SLC8A1-AS1 protects against myocardial damage through activation of cGMP-PKG signaling pathway by inhibiting SLC8A1 in mice models of myocardial infarction. J. Cell. Physiol. 234, 9019-9032. doi: 10.1002/jcp.27574

Guttman, M., Donaghey, J., Carey, B. W., Garber, M., Grenier, J. K., and Munson, G. (2011). lincRNAs act in the circuitry controlling pluripotency and differentiation. Nature 477, 295-300. doi: 10.1038/nature10398

Guttman, M., and Rinn, J. L. (2012). Modular regulatory principles of large non-coding RNAs. Nature 482, 339-346. doi: 10.1038/nature10887

Hao, K., Lei, W., Wu, H., Wu, J., Yang, Z., and Yan, S. (2019). LncRNA-Safe contributes to cardiac fibrosis through Safe-Sfrp2-HuR complex in mouse myocardial infarction. Theranostics 9, 7282-7297. doi: 10.7150/thno.33920

Hausenloy, D. J. (2012). Conditioning the heart to prevent myocardial reperfusion injury during PPCI. Eur. Heart J. Acute Cardiovasc. Care 1, 13-32. doi: 10.1177/ 2048872612438805

Helgadottir, A., Thorleifsson, G., Manolescu, A., Gretarsdottir, S., Blondal, T., and Jonasdottir, A. (2007). A common variant on chromosome 9p21 affects the risk of myocardial infarction. Science 316, 1491-1493. doi: 10.1126/science.11 42842

Hosen, M. R., Militello, G., Weirick, T., Ponomareva, Y., Dassanayaka, S., and Moore, J. B. T. (2018). Airn regulates Igf2bp2 translation in cardiomyocytes. Circ. Res. 122, 1347-1353. doi: 10.1161/circresaha.117.312215

Huang, C. K., Kafert-Kasting, S., and Thum, T. (2020). Preclinical and clinical development of noncoding RNA therapeutics for cardiovascular disease. Circ. Res. 126, 663-678. doi: 10.1161/circresaha.119.315856

Huang, P., Wang, L., Li, Q., Tian, X., Xu, J., and Xu, J. (2020). Atorvastatin enhances the therapeutic efficacy of mesenchymal stem cells-derived exosomes in acute myocardial infarction via up-regulating long non-coding RNA H19. Cardiovasc. Res. 116, 353-367. doi: 10.1093/cvr/cvz139

Hung, T., and Chang, H. Y. (2010). Long noncoding RNA in genome regulation: prospects and mechanisms. RNA Biol. 7, 582-585. doi: 10.4161/rna.7.5.13216

Jiao, L., Li, M., Shao, Y., Zhang, Y., Gong, M., and Yang, X. (2019). IncRNAZFAS1 induces mitochondria-mediated apoptosis by causing cytosolic $\mathrm{Ca}(2+)$ overload in myocardial infarction mice model. Cell Death Dis. 10:942. doi: 10.1038/s41419-019-2136-6

Khan, M., Nickoloff, E., Abramova, T., Johnson, J., Verma, S. K., and Krishnamurthy, P. (2015). Embryonic stem cell-derived exosomes promote endogenous repair mechanisms and enhance cardiac function following myocardial infarction. Circ. Res. 117, 52-64. doi: 10.1161/circresaha.117. 305990

Kim, W. Y., and Sharpless, N. E. (2006). The regulation of INK4/ARF in cancer and aging. Cell 127, 265-275. doi: 10.1016/j.cell.2006.10.003
Klattenhoff, C. A., Scheuermann, J. C., Surface, L. E., Bradley, R. K., Fields, P. A., and Steinhauser, M. L. (2013). Braveheart, a long noncoding RNA required for cardiovascular lineage commitment. Cell 152, 570-583. doi: 10.1016/j.cell.2013. 01.003

Koerner, M. V., Pauler, F. M., Huang, R., and Barlow, D. P. (2009). The function of non-coding RNAs in genomic imprinting. Development 136, 1771-1783. doi: $10.1242 / \mathrm{dev} .030403$

Kotake, Y., Nakagawa, T., Kitagawa, K., Suzuki, S., Liu, N., and Kitagawa, M. (2011). Long non-coding RNA ANRIL is required for the PRC2 recruitment to and silencing of p15(INK4B) tumor suppressor gene. Oncogene 30, 1956-1962. doi: 10.1038/onc.2010.568

Kretz, M., Siprashvili, Z., Chu, C., Webster, D. E., Zehnder, A., and Qu, K. (2013). Control of somatic tissue differentiation by the long non-coding RNA TINCR. Nature 493, 231-235. doi: 10.1038/nature11661

Kumarswamy, R., Bauters, C., Volkmann, I., Maury, F., Fetisch, J., and Holzmann, A. (2014). Circulating long noncoding RNA, LIPCAR, predicts survival in patients with heart failure. Circ. Res. 114, 1569-1575. doi: 10.1161/circresaha. 114.303915

Landmesser, U., Poller, W., Tsimikas, S., Most, P., Paneni, F., and Lüscher, T. F. (2020). From traditional pharmacological towards nucleic acid-based therapies for cardiovascular diseases. Eur. Heart J. 41, 3884-3899. doi: 10.1093/eurheartj/ ehaa229

Lee, J. H., Gao, C., Peng, G., Greer, C., Ren, S., and Wang, Y. (2011). Analysis of transcriptome complexity through RNA sequencing in normal and failing murine hearts. Circ. Res. 109, 1332-1341. doi: 10.1161/circresaha.111.249433

Lescroart, F., Chabab, S., Lin, X., Rulands, S., Paulissen, C., and Rodolosse, A. (2014). Early lineage restriction in temporally distinct populations of Mesp1 progenitors during mammalian heart development. Nat. Cell. Biol. 16, 829-840. doi: $10.1038 /$ ncb3024

Levy, J. M., Yeh, W. H., Pendse, N., Davis, J. R., Hennessey, E., and Butcher, R. (2020). Cytosine and adenine base editing of the brain, liver, retina, heart and skeletal muscle of mice via adeno-associated viruses. Nat. Biomed. Eng. 4, 97-110. doi: 10.1038/s41551-019-0501-5

Lewis, E. F., Moye, L. A., Rouleau, J. L., Sacks, F. M., Arnold, J. M., and Warnica, J. W. (2003). Predictors of late development of heart failure in stable survivors of myocardial infarction: the CARE study. J. Am. Coll. Cardiol. 42, 1446-1453. doi: 10.1016/s0735-1097(03)01057-x

Li, X., Luo, S., Zhang, J., Yuan, Y., Jiang, W., and Zhu, H. (2019). IncRNA H19 alleviated myocardial I/RI via suppressing miR-877-3p/Bcl-2-mediated mitochondrial apoptosis. Mol. Ther. Nucleic Acids 17, 297-309. doi: 10.1016/ j.omtn.2019.05.031

Lin, L., Yang, Z., Zheng, G., Zhuansun, Y., Wang, Y., and Li, J. (2018). Analyses of changes in myocardial long non-coding RNA and mRNA profiles after severe hemorrhagic shock and resuscitation via RNA sequencing in a rat model. $B M C$ Mol. Biol. 19:11. doi: 10.1186/s12867-018-0113-8

Liu, C. Y., Zhang, Y. H., Li, R. B., Zhou, L. Y., An, T., and Zhang, R. C. (2018). LncRNA CAIF inhibits autophagy and attenuates myocardial infarction by blocking p53-mediated myocardin transcription. Nat. Commun. 9:29. doi: 10. 1038/s41467-017-02280-y

Liu, Y., Li, G., Lu, H., Li, W., Li, X., and Liu, H. (2014). Expression profiling and ontology analysis of long noncoding RNAs in post-ischemic heart and their implied roles in ischemia/reperfusion injury. Gene 543, 15-21. doi: 10.1016/j. gene.2014.04.016

Lou, Z., Wu, W., Chen, R., Xia, J., Shi, H., and Ge, H. (2021). Microarray analysis reveals a potential role of lncRNA expression in remote ischemic preconditioning in myocardial ischemia-reperfusion injury. Am. J. Transl. Res. $13,234-252$.

Luo, B., He, Z., Huang, S., Wang, J., Han, D., and Xue, H. (2020). Long non-coding RNA 554 promotes cardiac fibrosis via TGF- $\beta 1$ pathway in mice following myocardial infarction. Front. Pharmacol. 11:585680. doi: 10.3389/fphar.2020. 585680

Luo, H., Wang, J., Liu, D., Zang, S., Ma, N., and Zhao, L. (2019). The lncRNA H19/miR-675 axis regulates myocardial ischemic and reperfusion injury by targeting PPAR $\alpha$. Mol. Immunol. 105, 46-54. doi: 10.1016/j.molimm.2018. 11.011

Luo, S., Zhang, M., Wu, H., Ding, X., Li, D., and Dong, X. (2021). SAIL: a new conserved anti-fibrotic IncRNA in the heart. Basic Res. Cardiol. 116:15. doi: 10.1007/s00395-021-00854-y 
Ma, L., Bajic, V. B., and Zhang, Z. (2013). On the classification of long non-coding RNAs. RNA Biol. 10, 925-933. doi: 10.4161/rna.24604

Mao, Q., Liang, X. L., Zhang, C. L., Pang, Y. H., and Lu, Y. X. (2019). LncRNA KLF3-AS1 in human mesenchymal stem cell-derived exosomes ameliorates pyroptosis of cardiomyocytes and myocardial infarction through miR-1385p/Sirt1 axis. Stem Cell Res. Ther. 10:393. doi: 10.1186/s13287-019-1522-4

Marchant, D. J., Boyd, J. H., Lin, D. C., Granville, D. J., Garmaroudi, F. S., and Mcmanus, B. M. (2012). Inflammation in myocardial diseases. Circ. Res. 110, 126-144. doi: 10.1161/circresaha.111.243170

Matkovich, S. J., Edwards, J. R., Grossenheider, T. C., De Guzman Strong, C., and Dorn, G. W. II (2014). Epigenetic coordination of embryonic heart transcription by dynamically regulated long noncoding RNAs. Proc. Natl. Acad. Sci. U.S.A. 111, 12264-12269. doi: 10.1073/pnas.1410622111

Meng, K., Jiao, J., Zhu, R. R., Wang, B. Y., Mao, X. B., and Zhong, Y. C. (2020). The long noncoding RNA hotair regulates oxidative stress and cardiac myocyte apoptosis during ischemia-reperfusion injury. Oxid. Med. Cell. Longev. 2020:1645249. doi: 10.1155/2020/1645249

Mercola, M., Ruiz-Lozano, P., and Schneider, M. D. (2011). Cardiac muscle regeneration: lessons from development. Genes Dev. 25, 299-309. doi: 10.1101/ gad.2018411

Micheletti, R., Plaisance, I., Abraham, B. J., Sarre, A., Ting, C. C., and Alexanian, M. (2017). The long noncoding RNA Wisper controls cardiac fibrosis and remodeling. Sci. Transl. Med. 9:eaai9118. doi: 10.1126/scitranslmed.aai9118

Minamino, T., and Komuro, I. (2007). Vascular cell senescence: contribution to atherosclerosis. Circ. Res. 100, 15-26. doi: 10.1161/01.RES.0000256837.40544.4a

Moran, V. A., Perera, R. J., and Khalil, A. M. (2012). Emerging functional and mechanistic paradigms of mammalian long non-coding RNAs. Nucleic Acids Res. 40, 6391-6400. doi: 10.1093/nar/gks296

Nagano, T., and Fraser, P. (2011). No-nonsense functions for long noncoding RNAs. Cell 145, 178-181. doi: 10.1016/j.cell.2011.03.014

Ng, S. Y., Johnson, R., and Stanton, L. W. (2012). Human long non-coding RNAs promote pluripotency and neuronal differentiation by association with chromatin modifiers and transcription factors. EMBO J. 31, 522-533. doi: 10. 1038/emboj.2011.459

Niu, X., Pu, S., Ling, C., Xu, J., Wang, J., and Sun, S. (2020). lncRNA Oip5-as1 attenuates myocardial ischaemia/reperfusion injury by sponging miR-29a to activate the SIRT1/AMPK/PGC1 $\alpha$ pathway. Cell Prolif. 53:e12818. doi: 10.1111/ cpr. 12818

Ørom, U. A., Derrien, T., Beringer, M., Gumireddy, K., Gardini, A., and Bussotti, G. (2010). Long noncoding RNAs with enhancer-like function in human cells. Cell 143, 46-58. doi: 10.1016/j.cell.2010.09.001

Ounzain, S., Micheletti, R., Beckmann, T., Schroen, B., Alexanian, M., and Pezzuto, I. (2015). Genome-wide profiling of the cardiac transcriptome after myocardial infarction identifies novel heart-specific long non-coding RNAs. Eur. Heart J. 36, 353a-368a. doi: 10.1093/eurheartj/ehu180

Pacak, C. A., Mah, C. S., Thattaliyath, B. D., Conlon, T. J., Lewis, M. A., and Cloutier, D. E. (2006). Recombinant adeno-associated virus serotype 9 leads to preferential cardiac transduction in vivo. Circ. Res. 99, e3-e9. doi: 10.1161/01. RES.0000237661.18885.f6

Pandey, R. R., Mondal, T., Mohammad, F., Enroth, S., Redrup, L., and Komorowski, J. (2008). Kcnq1ot1 antisense noncoding RNA mediates lineagespecific transcriptional silencing through chromatin-level regulation. Mol. Cell 32, 232-246. doi: 10.1016/j.molcel.2008.08.022

Partridge, E. C., Chhetri, S. B., Prokop, J. W., Ramaker, R. C., Jansen, C. S., and Goh, S. T. (2020). Occupancy maps of 208 chromatin-associated proteins in one human cell type. Nature 583, 720-728. doi: 10.1038/s41586-020-2023-4

Pauli, A., Rinn, J. L., and Schier, A. F. (2011). Non-coding RNAs as regulators of embryogenesis. Nat. Rev. Genet. 12, 136-149. doi: 10.1038/nrg2904

Ponnusamy, M., Liu, F., Zhang, Y. H., Li, R. B., Zhai, M., and Liu, F. (2019). Long noncoding RNA CPR (cardiomyocyte proliferation regulator) regulates cardiomyocyte proliferation and cardiac repair. Circulation 139, 2668-2684. doi: $10.1161 /$ circulationaha.118.035832

Ponting, C. P., Oliver, P. L., and Reik, W. (2009). Evolution and functions of long noncoding RNAs. Cell 136, 629-641. doi: 10.1016/j.cell.2009.02.006

Ransohoff, J. D., Wei, Y., and Khavari, P. A. (2018). The functions and unique features of long intergenic non-coding RNA. Nat. Rev. Mol. Cell. Biol. 19, 143-157. doi: 10.1038/nrm.2017.104
Ribeiro, D. M., Zanzoni, A., Cipriano, A., Delli Ponti, R., Spinelli, L., and Ballarino, M. (2018). Protein complex scaffolding predicted as a prevalent function of long non-coding RNAs. Nucleic Acids Res. 46, 917-928. doi: 10.1093/nar/gkx1169

Rincon, M. Y., Vandendriessche, T., and Chuah, M. K. (2015). Gene therapy for cardiovascular disease: advances in vector development, targeting, and delivery for clinical translation. Cardiovasc. Res. 108, 4-20. doi: 10.1093/cvr/cvv205

Rinn, J. L., and Chang, H. Y. (2012). Genome regulation by long noncoding RNAs. Annu. Rev. Biochem. 81, 145-166. doi: 10.1146/annurev-biochem-051410092902

Rizki, G., and Boyer, L. A. (2015). Lncing epigenetic control of transcription to cardiovascular development and disease. Circ. Res. 117, 192-206. doi: 10.1161/ circresaha.117.304156

Sahoo, S., Kariya, T., and Ishikawa, K. (2021). Targeted delivery of therapeutic agents to the heart. Nat. Rev. Cardiol. 18, 389-399. doi: 10.1038/s41569-02000499-9

Schmitz, S. U., Grote, P., and Herrmann, B. G. (2016). Mechanisms of long noncoding RNA function in development and disease. Cell. Mol. Life Sci. 73, 2491-2509. doi: 10.1007/s00018-016-2174-5

Schonrock, N., Harvey, R. P., and Mattick, J. S. (2012). Long noncoding RNAs in cardiac development and pathophysiology. Circ. Res. 111, 1349-1362. doi: 10.1161/circresaha.112.268953

Schulte, C., Barwari, T., Joshi, A., Zeller, T., and Mayr, M. (2020). Noncoding RNAs versus protein biomarkers in cardiovascular disease. Trends Mol. Med. 26, 583-596. doi: 10.1016/j.molmed.2020.02.001

Shabalina, S. A., and Spiridonov, N. A. (2004). The mammalian transcriptome and the function of non-coding DNA sequences. Genome Biol. 5:105. doi: 10.1186/ gb-2004-5-4-105

Shi, H., Sun, H., Li, J., Bai, Z., Wu, J., and Li, X. (2020). Systematic analysis of lncRNA and microRNA dynamic features reveals diagnostic and prognostic biomarkers of myocardial infarction. Aging (Albany N. Y.) 12, 945-964. doi: 10.18632/aging. 102667

Shi, H. J., Wang, M. W., Sun, J. T., Wang, H., Li, Y. F., and Chen, B. R. (2019). A novel long noncoding RNA FAF inhibits apoptosis via upregulating FGF9 through PI3K/AKT signaling pathway in ischemia-hypoxia cardiomyocytes. J. Cell. Physiol. 234, 21973-21987. doi: 10.1002/jcp.28760

Srivastava, D. (2006). Making or breaking the heart: from lineage determination to morphogenesis. Cell 126, 1037-1048. doi: 10.1016/j.cell.2006.09.003

Sun, L., Zhu, W., Zhao, P., Wang, Q., Fan, B., and Zhu, Y. (2020). Long noncoding RNA UCA1 from hypoxia-conditioned hMSC-derived exosomes: a novel molecular target for cardioprotection through miR-873-5p/XIAP axis. Cell Death Dis. 11:696. doi: 10.1038/s41419-020-02783-5

Thum, T. (2018). Translational opportunities and challenges of long noncoding RNAs in cardiac regeneration. J. Am. Coll. Cardiol. 72, 551-552. doi: 10.1016/j. jacc.2018.05.039

Thum, T., and Condorelli, G. (2015). Long noncoding RNAs and microRNAs in cardiovascular pathophysiology. Circ. Res. 116, 751-762. doi: 10.1161/ circresaha.116.303549

Thygesen, K., Alpert, J. S., Jaffe, A. S., Chaitman, B. R., Bax, J. J., and Morrow, D. A. (2018). Fourth universal definition of myocardial infarction (2018). J. Am. Coll. Cardiol. 72, 2231-2264. doi: 10.1016/j.jacc.2018.08.1038

Tkach, M., and Théry, C. (2016). Communication by extracellular vesicles: where we are and where we need to go. Cell 164, 1226-1232. doi: 10.1016/j.cell.2016. 01.043

Travers, J. G., Kamal, F. A., Robbins, J., Yutzey, K. E., and Blaxall, B. C. (2016). Cardiac fibrosis: the fibroblast awakens. Circ. Res. 118, 1021-1040. doi: 10.1161/ circresaha.115.306565

Trembinski, D. J., Bink, D. I., Theodorou, K., Sommer, J., Fischer, A., and Van Bergen, A. (2020). Aging-regulated anti-apoptotic long non-coding RNA Sarrah augments recovery from acute myocardial infarction. Nat. Commun. 11:2039. doi: 10.1038/s41467-020-15995-2

Valadi, H., Ekström, K., Bossios, A., Sjöstrand, M., Lee, J. J., and Lötvall, J. O. (2007). Exosome-mediated transfer of mRNAs and microRNAs is a novel mechanism of genetic exchange between cells. Nat. Cell Biol. 9, 654-659. doi: 10.1038/nc b1596

van den Borne, S. W., Diez, J., Blankesteijn, W. M., Verjans, J., Hofstra, L., and Narula, J. (2010). Myocardial remodeling after infarction: the role of myofibroblasts. Nat. Rev. Cardiol. 7, 30-37. doi: 10.1038/nrcardio.2 009.199 
Van Nostrand, E. L., Freese, P., Pratt, G. A., Wang, X., Wei, X., and Xiao, R. (2020). A large-scale binding and functional map of human RNA-binding proteins. Nature 583, 711-719. doi: 10.1038/s41586-020-2077-3

Vausort, M., Wagner, D. R., and Devaux, Y. (2014). Long noncoding RNAs in patients with acute myocardial infarction. Circ. Res. 115, 668-677. doi: 10.1161/ circresaha.115.303836

Velagaleti, R. S., Pencina, M. J., Murabito, J. M., Wang, T. J., Parikh, N. I., and D'agostino, R. B. (2008). Long-term trends in the incidence of heart failure after myocardial infarction. Circulation 118, 2057-2062. doi: 10.1161/circulationaha. 108.784215

Viereck, J., Kumarswamy, R., Foinquinos, A., Xiao, K., Avramopoulos, P., and Kunz, M. (2016). Long noncoding RNA Chast promotes cardiac remodeling. Sci. Transl. Med. 8:326ra322. doi: 10.1126/scitranslmed.aaf1475

Wamstad, J. A., Alexander, J. M., Truty, R. M., Shrikumar, A., Li, F., and Eilertson, K. E. (2012). Dynamic and coordinated epigenetic regulation of developmental transitions in the cardiac lineage. Cell 151, 206-220. doi: 10.1016/j.cell.2012. 07.035

Wang, J. X., Zhang, X. J., Li, Q., Wang, K., Wang, Y., and Jiao, J. Q. (2015). MicroRNA-103/107 regulate programmed necrosis and myocardial ischemia/reperfusion injury through targeting FADD. Circ. Res. 117, 352-363. doi: 10.1161/circresaha.117.305781

Wang, K., Liu, C. Y., Zhou, L. Y., Wang, J. X., Wang, M., and Zhao, B. (2015). APF lncRNA regulates autophagy and myocardial infarction by targeting miR-1883p. Nat. Commun. 6:6779. doi: 10.1038/ncomms7779

Wang, K., Liu, F., Liu, C. Y., An, T., Zhang, J., and Zhou, L. Y. (2016). The long noncoding RNA NRF regulates programmed necrosis and myocardial injury during ischemia and reperfusion by targeting miR-873. Cell Death Differ. 23, 1394-1405. doi: 10.1038/cdd.2016.28

Wang, K., Long, B., Zhou, L. Y., Liu, F., Zhou, Q. Y., and Liu, C. Y. (2014). CARL IncRNA inhibits anoxia-induced mitochondrial fission and apoptosis in cardiomyocytes by impairing miR-539-dependent PHB2 downregulation. Nat. Commun. 5:3596. doi: 10.1038/ncomms4596

Wang, K. C., and Chang, H. Y. (2011). Molecular mechanisms of long noncoding RNAs. Mol. Cell 43, 904-914. doi: 10.1016/j.molcel.2011.08.018

Wang, L., and Zhang, J. (2020). Exosomal lncRNA AK139128 derived from hypoxic cardiomyocytes promotes apoptosis and inhibits cell proliferation in cardiac fibroblasts. Int. J. Nanomedicine 15, 3363-3376. doi: 10.2147/ijn.S240660

Wang, Q. S., Zhou, J., and Li, X. (2020). LncRNA UCA1 protects cardiomyocytes against hypoxia/reoxygenation induced apoptosis through inhibiting miR143/MDM2/p53 axis. Genomics 112, 574-580. doi: 10.1016/j.ygeno.2019. 04.009

Wang, X., Wang, L., Ma, Z., Liang, W., Li, J., and Li, Y. (2020). Early expressed circulating long noncoding RNA CHAST is associated with cardiac contractile function in patients with acute myocardial infarction. Int. J. Cardiol. 302, 15-20. doi: 10.1016/j.ijcard.2019.12.058

Wang, Y., Yang, X., Jiang, A., Wang, W., Li, J., and Wen, J. (2019). Methylationdependent transcriptional repression of RUNX3 by KCNQ1OT1 regulates mouse cardiac microvascular endothelial cell viability and inflammatory response following myocardial infarction. FASEB J. 33, 13145-13160. doi: 10. 1096/fj.201900310R

Wapinski, O., and Chang, H. Y. (2011). Long noncoding RNAs and human disease. Trends Cell Biol. 21, 354-361. doi: 10.1016/j.tcb.2011.04.001

Warner, K. D., Hajdin, C. E., and Weeks, K. M. (2018). Principles for targeting RNA with drug-like small molecules. Nat. Rev. Drug Discov. 17, 547-558. doi: 10.1038/nrd.2018.93

Yang, K. C., Yamada, K. A., Patel, A. Y., Topkara, V. K., George, I., and Cheema, F. H. (2014). Deep RNA sequencing reveals dynamic regulation of myocardial noncoding RNAs in failing human heart and remodeling with mechanical circulatory support. Circulation 129, 1009-1021. doi: 10.1161/circulationaha. 113.003863

Yang, Y. J., Qian, H. Y., Huang, J., Geng, Y. J., Gao, R. L., and Dou, K. F. (2008). Atorvastatin treatment improves survival and effects of implanted mesenchymal stem cells in post-infarct swine hearts. Eur. Heart J. 29, 15781590. doi: 10.1093/eurheartj/ehn167

Yang, Y. J., Qian, H. Y., Huang, J., Li, J. J., Gao, R. L., and Dou, K. F. (2009). Combined therapy with simvastatin and bone marrow-derived mesenchymal stem cells increases benefits in infarcted swine hearts. Arterioscler. Thromb. Vasc. Biol. 29, 2076-2082. doi: 10.1161/atvbaha.109.189662

Yellon, D. M., and Hausenloy, D. J. (2007). Myocardial reperfusion injury. N. Engl. J. Med. 357, 1121-1135. doi: 10.1056/NEJMra071667

Ylä-Herttuala, S., and Alitalo, K. (2003). Gene transfer as a tool to induce therapeutic vascular growth. Nat. Med. 9, 694-701. doi: 10.1038/nm06 03-694

Yoon, J. H., Abdelmohsen, K., and Gorospe, M. (2014). Functional interactions among microRNAs and long noncoding RNAs. Semin Cell Dev. Biol. 34, 9-14. doi: 10.1016/j.semcdb.2014.05.015

Yu, A. M., Choi, Y. H., and Tu, M. J. (2020). RNA drugs and RNA targets for small molecules: principles, progress, and challenges. Pharmacol. Rev. 72, 862-898. doi: 10.1124/pr.120.019554

Yu, J., Yang, Y., Xu, Z., Lan, C., Chen, C., and Li, C. (2020). Long noncoding RNA Ahit protects against cardiac hypertrophy through SUZ12 (suppressor of Zeste 12 protein homolog)-mediated downregulation of MEF2A (myocyte enhancer factor 2A). Circ. Heart Fail. 13:e006525. doi: 10.1161/circheartfailure. 119.006525

Zangrando, J., Zhang, L., Vausort, M., Maskali, F., Marie, P. Y., and Wagner, D. R. (2014). Identification of candidate long non-coding RNAs in response to myocardial infarction. BMC Genomics 15:460. doi: 10.1186/1471-21 64-15-460

Zhang, C., Ge, S., Gong, W., Xu, J., Guo, Z., and Liu, Z. (2020). LncRNA ANRIL acts as a modular scaffold of WDR5 and HDAC3 complexes and promotes alteration of the vascular smooth muscle cell phenotype. Cell Death Dis. 11:435. doi: 10.1038/s41419-020-2645-3

Zhang, F., Fu, X., Kataoka, M., Liu, N., Wang, Y., and Gao, F. (2021). Long noncoding RNA Cfast regulates cardiac fibrosis. Mol. Ther. Nucleic Acids 23, 377-392. doi: 10.1016/j.omtn.2020.11.013

Zhang, X., Chen, Z., Zang, J., Yao, C., Shi, J., and Nie, R. (2021). LncRNA-mRNA co-expression analysis discovered the diagnostic and prognostic biomarkers and potential therapeutic agents for myocardial infarction. Aging (Albany N. Y.) 13, 8944-8959. doi: 10.18632/aging.202713

Zhang, Y., Jiao, L., Sun, L., Li, Y., Gao, Y., and Xu, C. (2018). LncRNA ZFAS1 as a SERCA2a inhibitor to cause intracellular $\mathrm{Ca}(2+)$ overload and contractile dysfunction in a mouse model of myocardial infarction. Circ. Res. 122, 13541368. doi: 10.1161/CIRCRESAHA.117.312117

Zhang, Y., Sun, L., Xuan, L., Pan, Z., Li, K., and Liu, S. (2016). Reciprocal changes of circulating long non-coding RNAs ZFAS1 and CDR1AS predict acute myocardial infarction. Sci. Rep. 6:22384. doi: 10.1038/srep 22384

Zhang, Y., Zhang, X., Cai, B., Li, Y., Jiang, Y., and Fu, X. (2021). The long noncoding RNA lncCIRBIL disrupts the nuclear translocation of Bclaf1 alleviating cardiac ischemia-reperfusion injury. Nat. Commun. 12:522. doi: 10. 1038/s41467-020-20844-3

Zheng, M. L., Liu, X. Y., Han, R. J., Yuan, W., Sun, K., and Zhong, J. C. (2020). Circulating exosomal long non-coding RNAs in patients with acute myocardial infarction. J. Cell. Mol. Med. 24, 9388-9396. doi: 10.1111/jcm m.15589

Conflict of Interest: The authors declare that the research was conducted in the absence of any commercial or financial relationships that could be construed as a potential conflict of interest.

Publisher's Note: All claims expressed in this article are solely those of the authors and do not necessarily represent those of their affiliated organizations, or those of the publisher, the editors and the reviewers. Any product that may be evaluated in this article, or claim that may be made by its manufacturer, is not guaranteed or endorsed by the publisher.

Copyright (c) 2021 Xie, Zhang, Mao, Zhang and Li. This is an open-access article distributed under the terms of the Creative Commons Attribution License (CC BY). The use, distribution or reproduction in other forums is permitted, provided the original author(s) and the copyright owner(s) are credited and that the original publication in this journal is cited, in accordance with accepted academic practice. No use, distribution or reproduction is permitted which does not comply with these terms. 